\title{
Birth preparedness and complication readiness among pregnant women admitted in a rural hospital in Rwanda
}

\author{
Patrick Smeele ${ }^{1}$, Richard Kalisa ${ }^{2,3}$, Marianne van Elteren ${ }^{1}$, Jos van Roosmalen ${ }^{3,4}$ and Thomas van den Akker ${ }^{4 *}$ (D)
}

\begin{abstract}
Background: With an aim to prevent adverse pregnancy outcomes, 'birth preparedness and complication readiness' (BP/CR) promotes timely access to skilled maternal and neonatal services. Objective of this study was to assess implementation of BP/CR among pregnant women admitted with obstetric emergencies in rural Rwanda.

Methods: A cross-sectional study among pregnant women who were referred to Ruhengeri hospital between July and November 2015. The 'Safe Motherhood questionnaire' as developed by Jhpiego's Maternal and Neonatal Health Program was used to collect data. Women were asked to mention key danger signs and respond as to whether they had identified: (A) skilled birth attendant, (B) location to give birth, (C) mode of transport, (D) money to cover health care expenditure. Women who answered 'yes' to three or four items were labeled 'well prepared'. Multivariate logistic regression analysis was conducted to compare the 'well prepared' and 'less prepared'.

Results: With regard to complication readiness, out of 350 women, 296 (84.6\%), 271 (77.4\%) and 288 (82.3\%) could mention at least one key danger sign during pregnancy, labor and postpartum respectively, but only 23 (6.6\%) could mention three or more key danger signs during all three periods. With regard to birth preparedness, 46 (13.1\%) women had identified a skilled birth attendant, 68 (19.4\%) birth location, 76 (21.7\%) mode of transport, and 306 (87.4\%) had saved money for health care costs. Seventy-eight women (22.3\%) were 'well prepared', associated factors being first time pregnancy (adjusted Odds Ratio $(\mathrm{aOR})=3.2 ; 95 \% \mathrm{Cl} ; 1.2-5.8$ ), knowledge of at least two danger signs $(\mathrm{aOR}=2.8 ; 95 \% \mathrm{Cl} ; 1.7-3.9)$ and having been assisted by a community health worker at the antenatal clinic $(\mathrm{aOR}=2.2,95 \% \mathrm{Cl} ; 1.3-3.7)$.
\end{abstract}

Conclusion: Knowledge of obstetric danger signs was suboptimal and birth preparedness low. We recommend review of practices regarding health promotion in antenatal care, taking care not to exclude multiparous women from messages related to birth preparedness, and do promote use of community health workers to enhance effectiveness of $B P / C R$.

Keywords: Birth preparedness, Complication readiness, Obstetrics, High-risk pregnancy, Health promotion, Rwanda

\section{Background}

Maternal mortality remains a major global concern, especially in sub-Saharan Africa where the maternal mortality ratio, although declining, is still high [1-3]. One of the reasons is lack of Birth Preparedness and Complication Readiness (BP/CR), which is recognized as

\footnotetext{
*Correspondence: t.h.van_den_akker@lumc.nl

${ }^{4}$ Department of Obstetrics, Leiden University Medical Center, Leiden, the Netherlands

Full list of author information is available at the end of the article
}

a key component of safe motherhood programs around the world $[4,5]$.

$\mathrm{BP} / \mathrm{CR}$ is a comprehensive package to promote timely access to skilled maternal and neonatal health services. It also promotes active preparation and decision making for birth among pregnant women and their families [5-7]. A birth plan includes identifying a skilled birth attendant and location of the closest appropriate care facility, saving funds for birth-related and emergency expenses, arranging transport to a health facility for birth and obstetric emergencies and identification of compatible blood donors in

(C) The Author(s). 2018 Open Access This article is distributed under the terms of the Creative Commons Attribution 4.0 International License (http://creativecommons.org/licenses/by/4.0/), which permits unrestricted use, distribution, and 
case of need [5]. The latter criterion does not apply in Rwanda, where centralized blood banks taking blood from voluntary donors are in place [8].

Whilst $\mathrm{BP} / \mathrm{CR}$ has been associated with reduced maternal and neonatal mortality [9], improved preventive behaviors [10-12], increased knowledge of danger signs [13-15] and more frequent seeking of professional care during emergencies [11, 16, 17], previous studies have shown low rates of $\mathrm{BP} / \mathrm{CR}$ among women in Uganda [18], Ethiopia [4, 14, 15] and Burkina Faso [19]. The rate of $\mathrm{BP} / \mathrm{CR}$ among women in Rwanda is unknown.

In 2003, Rwanda adopted BP/CR as part of 'focused antenatal care' to increase access to skilled birth attendance [20,21]. Part of this strategy is that health workers explain women the obstetric danger signs that may occur during pregnancy, childbirth and the postpartum period as well as methods to prevent mother-to-child transmission of HIV [20]. The introduction of focused antenatal care may have contributed to the reduction of the maternal mortality ratio by roughly two-thirds from 750 in 2005 to 210 per 100,000 live births in 2015 and to the increased skilled birth attendance rate from 28 to $91 \%$ [22, 23].

This study aimed to assess practices around and factors associated with $\mathrm{BP} / \mathrm{CR}$ among pregnant women admitted with obstetric emergencies in a rural Rwandan hospital.

\section{Methods}

\section{Design}

This was a cross-sectional study among pregnant women who were referred for obstetric emergencies to Ruhengeri hospital, Musanze district, Rwanda, between July and November 2015.

\section{Setting}

According to the Population Census, Musanze district had a population of 368,267 inhabitants with a total fertility rate of 4.6 births per woman in 2012. Health insurance coverage was $85.1 \%$, and $65.3 \%$ of women who gave birth with assistance from a skilled birth attendant. Uptake of postnatal care by skilled personnel was 4.5\% [24]. Health promotion and counseling as part of BP/CR are provided by community health workers in addition to other facility-based professionals. Community health workers sometimes escort laboring women to health facilities.

Ruhengeri hospital acts as a provincial referral hospital for women with high-risk pregnancies and referrals from health centers and other district hospitals in the northern province. Medical services offered are covered by community-based health insurance ('Mutuelle de Santé') at contribution of an annual fee of RWF 3000 (US\$4.5), with a $10 \%$ surcharge for each episode of illness. In case of shortages of supplies, patients are requested to procure missing items from private pharmacies. During the study period, medical staff consisted of one specialist obstetrician, four medical officers, two intern doctors and 18 midwives.

\section{Data collection}

The study included all pregnant women who were referred to the maternity ward who consented to participation, using the consent form given in Additional file 1. Participants were followed up to discharge or death.

Two trained research assistants identified possible participants while the principal investigator verified suitability for study inclusion. The 'Safe Motherhood questionnaire' developed by the Maternal Neonatal Program of JHPIEGO, an affiliate of John Hopkins University [5] was used, and adapted to the local context to include a question regarding purchase of birth materials as a common birth preparedness practice (Additional file 1). The expert translator translated it from the English version to the local language (Kinyarwanda), and then another translator translated this text back into English to check whether the original meaning was still present.

The questionnaire pertained to socio-demographic variables such as age, residence, religion, education level, marital and employment status, and other variables with regard to antenatal care (including type of advice received and type of health worker seen), obstetric history, reasons for referral. With regard to knowledge of obstetric danger signs, we assessed whether a woman, when prompted, could mention danger signs and symptoms such as vaginal bleeding, fits, swelling of face or limbs, fever, loss of consciousness, headache, abdominal pain, prolonged labor and retained placenta.

Lastly, four 'BP/CR questions' verified whether the woman had taken one of the following four steps: A) identification of a skilled birth attendant, B) identification of the location of the closest appropriate care facility, C) identification of a means of transport to that facility, D) saving money for hospital costs/birth materials. Women answering 'yes' to at least three of these four BP/CR questions were labeled 'well prepared'. Remaining women were labeled 'less prepared'. We also assessed whether mentioning of at least two danger signs during pregnancy, childbirth or postpartum was associated with being well prepared.

\section{Data analysis}

Data were entered, coded, cleaned and analyzed using SPSS for Windows Version 18.0. After the initial descriptive analysis, bivariate analysis was done to test for associations between the dependent variable $\mathrm{BP} / \mathrm{CR}$ and independent variables using Pearson's chi square or Fischer's exact test. Factors that were found to have $p$-values below 0.2 in the bivariate analysis were entered into multivariable logistic 
regression model to compare women who were well prepared with those who were less prepared.

\section{Results}

Of all 350 women who were interviewed, mean age was 27.7 years. Characteristics are shown in Table 1.

All respondents had attended ANC at least once during this pregnancy; 131 women $(37.4 \%)$ had completed the recommended four or more antenatal visits. Mean antenatal visits were $2.9 \pm 0.9$. Almost two out of three women (59.4\%) had received education on the importance of knowing danger signs, knowing where to go in case of

Table 1 Socio-demographic and obstetric characteristics

\begin{tabular}{|c|c|c|}
\hline Characteristics & Number $(n)$ & Percent (\%) \\
\hline \multicolumn{3}{|l|}{ Age (Years) (Mean \pm SD; $27.7 \pm 6.0$ ) } \\
\hline$<20$ & 35 & 10.0 \\
\hline $21-29$ & 188 & 53.7 \\
\hline$>30$ & 127 & 36.3 \\
\hline \multicolumn{3}{|l|}{ Marital status } \\
\hline Married & 327 & 93.4 \\
\hline Not currently married ${ }^{\mathrm{a}}$ & 23 & 6.6 \\
\hline \multicolumn{3}{|l|}{ Residence (district) } \\
\hline Musanze & 267 & 76.3 \\
\hline Others $^{b}$ & 83 & 23.7 \\
\hline \multicolumn{3}{|l|}{ Education } \\
\hline None & 114 & 32.6 \\
\hline Primary & 193 & 55.1 \\
\hline Secondary and Above & 43 & 12.3 \\
\hline \multicolumn{3}{|l|}{ Occupation } \\
\hline Housewife & 195 & 55.7 \\
\hline Own business/private employee & 98 & 28.0 \\
\hline Government/salaried employee & 57 & 16.3 \\
\hline \multicolumn{3}{|l|}{ Religion } \\
\hline Christianity & 318 & 90.9 \\
\hline Islam & 32 & 9.1 \\
\hline \multicolumn{3}{|l|}{ Parity (Mean $\pm S D ; 2.6 \pm 1.9$ ) } \\
\hline 1 & 123 & 35.1 \\
\hline $2-4$ & 176 & 50.3 \\
\hline$>5$ & 51 & 14.6 \\
\hline \multicolumn{3}{|l|}{ Prior stillbirth } \\
\hline No & 290 & 82.9 \\
\hline Yes & 60 & 17.1 \\
\hline \multicolumn{3}{|l|}{ Travel time to health facility } \\
\hline$<1 \mathrm{~h}$ & 215 & 61.4 \\
\hline$\geq 1 \mathrm{~h}$ & 135 & 38.6 \\
\hline
\end{tabular}

Mean \pm Standard Deviation

${ }^{a}$ Single, divorced and widowed

Other $^{\mathrm{b}}$ Nyabihu/Rubavu/Burera/Gakeke complications (73.1\%) and where to give birth (76.3\%), identifying transport (67.1\%), identifying a skilled birth attendant $(17.7 \%)$ and saving money (76.9\%) (Table 2).

Regarding knowledge of key danger signs, vaginal bleeding was the most frequently mentioned complication by women during pregnancy (61.1\%), labor/birth (73.1\%) and postpartum (58\%) (Table 3). Prolonged labor, which is one of the leading causes of maternal morbidity, was reported by only $13.7 \%$. Most women knew at least one key danger sign during pregnancy $(n=296 ; 84.6 \%)$, labor/birth $(n=271 ; 77.4 \%)$ and postpartum $(n=288 ; 82.3 \%)$. Only 23 women $(6.6 \%)$ had knowledge of three or more key danger signs during the three periods.

In practice, 46 women $(13.1 \%)$ had identified a skilled birth attendant, $68(19.4 \%)$ a facility to give birth, and 76 $(21.7 \%)$ a means of transportation. Most women $(n=306$; 87.4\%) had saved money for hospital costs/birth materials

Table 2 Antenatal care uptake and advice given

\begin{tabular}{|c|c|c|}
\hline Characteristics & Number & Percent \\
\hline \multicolumn{3}{|c|}{ Antenatal attendance (Mean $\pm S D ; 2.9 \pm 0.9$ ) } \\
\hline$\geq 4$ & 131 & 37.4 \\
\hline $2-3$ & 185 & 52.9 \\
\hline 1 & 34 & 9.7 \\
\hline \multicolumn{3}{|c|}{ Gestational age at first antenatal visit } \\
\hline 1st trimester & 267 & 76.3 \\
\hline 2nd trimester & 60 & 17.1 \\
\hline 3rd trimester & 23 & 6.6 \\
\hline \multicolumn{3}{|l|}{ Personnel checked } \\
\hline Health professional & 147 & 41.7 \\
\hline Community health workers & 203 & 58.3 \\
\hline \multicolumn{3}{|c|}{ Advice on danger signs during pregnancy, childbirth, or postpartum } \\
\hline Yes & 208 & 59.4 \\
\hline No & 142 & 40.6 \\
\hline \multicolumn{3}{|c|}{ Advise on where to go if danger signs happen } \\
\hline Yes & 256 & 73.1 \\
\hline No & 94 & 26.9 \\
\hline \multicolumn{3}{|c|}{ Advise on identifying health facility } \\
\hline Yes & 267 & 76.3 \\
\hline No & 83 & 23.7 \\
\hline \multicolumn{3}{|c|}{ Advise on arrangement for transport } \\
\hline Yes & 235 & 67.1 \\
\hline No & 115 & 32.9 \\
\hline \multicolumn{3}{|c|}{ Advise on saving money for delivery or emergency } \\
\hline Yes & 269 & 76.9 \\
\hline No & 81 & 23.1 \\
\hline \multicolumn{3}{|c|}{ Advise on identifying skilled birth attendant } \\
\hline Yes & 62 & 17.7 \\
\hline No & 288 & 82.3 \\
\hline
\end{tabular}


Table 3 Women's awareness of obstetric danger signs during pregnancy, birth and postpartum

\begin{tabular}{|c|c|c|c|c|c|c|}
\hline \multirow[t]{3}{*}{ Obstetric danger signs } & \multicolumn{6}{|c|}{ Awareness } \\
\hline & \multicolumn{2}{|c|}{ Pregnancy } & \multicolumn{2}{|c|}{ Labor/Childbirth } & \multicolumn{2}{|c|}{ Postpartum } \\
\hline & $n$ & $\%$ & $n$ & $\%$ & $n$ & $\%$ \\
\hline Vaginal bleeding & 214 & 61.1 & 256 & 73.1 & 203 & 58.0 \\
\hline Fits of pregnancy & 15 & 4.3 & 11 & 3.1 & 2 & 0.6 \\
\hline Swelling of face/lower limbs & 52 & 14.9 & & & 98 & 28.0 \\
\hline High grade fever & 20 & 5.7 & 13 & 3.7 & 18 & 5.1 \\
\hline Loss of consciousness & 41 & 11.7 & 3 & 0.9 & 29 & 8.3 \\
\hline Severe headache & 39 & 11.1 & 19 & 5.4 & 67 & 19.1 \\
\hline Dizziness/blurred vision & 31 & 8.9 & & & 22 & 6.3 \\
\hline Severe abdominal pain & 50 & 14.3 & & & 46 & 13.1 \\
\hline Baby does not move & 22 & 6.3 & & & & \\
\hline Difficulty in breathing & 14 & 4.0 & & & 9 & 2.6 \\
\hline Severe weakness & 67 & 19.1 & & & 41 & 11.7 \\
\hline Water breaks without labor & 88 & 25.1 & & & & \\
\hline Prolonged labor & & & 48 & 13.7 & & \\
\hline Retained placenta & & & 125 & 35.7 & & \\
\hline Foul smelling vaginal discharge & & & & & 30 & 8.6 \\
\hline Do not know any of the above & 54 & 15.4 & 79 & 22.6 & 62 & 17.7 \\
\hline
\end{tabular}

(Table 4). About one in five women $(n=78 ; 22.3 \%)$ were considered 'well prepared' in terms of BP/CR.

The adjusted multivariate model showed that significant predictors for being well prepared were first time pregnancy (adjusted odds ratio $(\mathrm{aOR})=3.2 ; 95 \%$ CI 1.2-5.8), knowledge of at least two danger signs during pregnancy $(\mathrm{aOR}=2.8 ; 95 \%$ CI $1.7-3.9)$ and having seen a community health worker $(\mathrm{aOR}=2.2$, 95\% CI 1.3-3.7) (Table 5).

\section{Discussion}

Our findings show that involving community health workers in antenatal care, as well as counseling on danger signs during pregnancy may be two effective strategies to promote birth preparedness. Although factors such as advanced maternal age, higher education, better antenatal care attendance and occupation of a woman or her partner were previously found to be associated with increased $\mathrm{BP} / \mathrm{CR}$ in other studies $[12,15,25]$, this was not the case in our population.

Similar to other settings, a high proportion of women reported to have received advice on $\mathrm{BP} / \mathrm{CR}[13,18,19]$. This may be explained by the wide availability of community health workers throughout Rwanda. Community health workers engage women and their families into formulating birth plans on a one-to-one basis prior to childbirth [26]. Still, a number of women do miss out on $\mathrm{BP} / \mathrm{CR}$ advice, even if they attend antenatal care. Moreover, a considerable number of women had not followed the advice they were given, perhaps due to poor
Table 4 Birth preparedness among pregnant women

\begin{tabular}{lll}
\hline Level of birth preparedness & Number & Percent \\
\hline Identified health facility & 68 & 19.4 \\
Yes & 282 & 80.6 \\
No & & \\
Arranged for transport & 76 & 21.7 \\
$\quad$ Yes & 274 & 78.3 \\
No & & \\
Saved money & 306 & 87.4 \\
Yes & 44 & 12.6 \\
No & & \\
Identified skilled birth attendant & 46 & 13.1 \\
Yes & 304 & 86.9 \\
No & & \\
Number of steps taken & 81 & 23.1 \\
0 & 129 & 36.9 \\
1 & 62 & 17.7 \\
2 & 66 & 18.9 \\
3 & 12 & 3.4 \\
4 & 78 & 22.3 \\
At least 3 steps taken & &
\end{tabular}


Table 5 Characteristics of well-prepared ${ }^{a}$ women versus those less-prepared

\begin{tabular}{|c|c|c|c|c|}
\hline \multirow[t]{2}{*}{ Characteristics } & \multicolumn{2}{|c|}{ Birth preparedness } & \multirow[t]{2}{*}{ COR $(95 \%$ Cl) } & \multirow[t]{2}{*}{ baOR (95\% Cl) } \\
\hline & Well ${ }^{a}(n=78)$ & Less $(n=272)$ & & \\
\hline \multicolumn{5}{|l|}{ Age (Years) } \\
\hline$<25$ & $41(52.6)$ & $167(61.4)$ & $0.9(0.4-2.0)$ & $0.6(0.5-1.4)$ \\
\hline$\geq 25$ & $37(47.4)$ & 105 (38.6) & 1.0 & \\
\hline \multicolumn{5}{|l|}{ Marital status } \\
\hline Married & $70(89.7)$ & $257(94.5)$ & 1.0 & \\
\hline Not currently married ${ }^{c}$ & $8(10.3)$ & $15(5.5)$ & $2.0(0.8-4.8)$ & $1.2(0.3-4.2)$ \\
\hline \multicolumn{5}{|l|}{ Occupation } \\
\hline Irregular income & 66 (84.6) & $227(83.5)$ & 1.0 & \\
\hline Regular income & $12(15.4)$ & $45(16.5)$ & $1.0(0.4-1.9)$ & $0.7(0.3-2.1)$ \\
\hline \multicolumn{5}{|l|}{ Education } \\
\hline None or Primary & $68(87.2)$ & $239(87.9)$ & 1.0 & \\
\hline Secondary and above & $10(12.8)$ & $33(12.1)$ & $1.3(0.5-3.0)$ & $0.8(0.5-1.1)$ \\
\hline \multicolumn{5}{|l|}{ Parity } \\
\hline 1 & $38(48.7)$ & $85(31.3)$ & $2.5(1.4-4.3)$ & $3.2(1.2-5.8)$ \\
\hline $2-4$ & 27 (34.6) & $149(54.8)$ & 1.0 & \\
\hline$\geq 5$ & $13(16.7)$ & $38(13.9)$ & $1.9(0.9-4.0)$ & $0.7(0.3-1.3)$ \\
\hline \multicolumn{5}{|l|}{ Prior stillbirth } \\
\hline No & $64(82.1)$ & $226(83.1)$ & 1.0 & \\
\hline Yes & $14(17.9)$ & $46(16.9)$ & $1.1(0.5-2.0)$ & $0.8(0.5-1.4)$ \\
\hline \multicolumn{5}{|l|}{ Antenatal attendance } \\
\hline$<4$ times & $3(3.8)$ & $216(79.4)$ & 1.0 & 1.0 \\
\hline$\geq 4$ times & $75(96.2)$ & 56 (20.6) & $1.9(1.7-2.4)$ & $1.3(0.8-2.1)$ \\
\hline \multicolumn{5}{|l|}{ Personnel checked during ANC } \\
\hline Health professional & $22(28.2)$ & $125(46.0)$ & 1.0 & 1.0 \\
\hline Community health worker & $56(71.8)$ & $147(54.0)$ & $1.4(1.2-1.9)$ & $2.2(1.3-3.7)$ \\
\hline \multicolumn{5}{|c|}{ Knowledge of at least 2 danger signs during pregnancy } \\
\hline Yes & $41(52.6)$ & $70(25.7)$ & $3.1(2.2-4.6)$ & $2.8(1.7-3.9)$ \\
\hline No & $37(47.4)$ & $202(74.3)$ & 1.0 & 1.0 \\
\hline \multicolumn{5}{|c|}{ Knowledge of at least 2 danger signs during childbirth } \\
\hline Yes & $31(39.7)$ & $27(9.9)$ & $2.3(1.1-4.6)$ & $1.6(0.8-2.7)$ \\
\hline No & $47(60.3)$ & $245(90.1)$ & 1.0 & \\
\hline \multicolumn{5}{|c|}{ Knowledge of at least 2 danger signs during postpartum } \\
\hline Yes & $16(20.5)$ & $38(14.0)$ & $1.5(0.8-2.8)$ & $0.8(0.5-1.4)$ \\
\hline No & $62(79.5)$ & 234 (86.0) & 1.0 & \\
\hline
\end{tabular}

Cl confidence interval, $O R$ odds ratio

${ }^{\text {a Any }} 3$ of 4 steps: identified a skilled birth attendant, identified a health facility, arranged for transport and saved money for emergency

${ }^{\mathrm{b}}$ Adjusted for all the independent variables indicated in the table

'Single, divorced and widowed

understanding of what the components of $\mathrm{BP} / \mathrm{CR}$ actually entail, or to poor delivery of the messages. This finding stresses the importance of improved training for health providers on how to better communicate BP/CRrelated messages and the need to address additional barriers to the uptake of $\mathrm{BP} / \mathrm{CR}$.
There were marked differences with regard to how frequent various danger signs were mentioned. In line with previous reports by others, vaginal bleeding during pregnancy, childbirth and postpartum was the most commonly reported key danger sign [16, 18]. On the contrary, prolonged labor, which is another leading cause 
of maternal deaths in Rwanda [22, 23] was mentioned by only few women in this study.

Our findings indicated low levels of knowledge of danger signs and birth preparedness respectively, lower than in other low-income countries $[14,18]$. This may be due to our facility-based rather than community-based study setting. In addition, we applied the criterion of three out of four BP/CR components for being 'well prepared', where another study applied three out of five [14]. Nevertheless, the underlying principles and methods used to study BP/CR are the same.

Nulliparous women were better prepared than multiparous women, perhaps due to the misconception that after the first pregnancy $\mathrm{BP} / \mathrm{CR}$ may not be required anymore. This is an indication that the frequency or quality of $\mathrm{BP} / \mathrm{CR}$ messages given to multiparous women may be reduced, although these should clearly aim to also target multiparous women.

Women who knew at least two key danger signs were found more likely to be well prepared, which is similar to previous studies $[12,16,18]$. This illustrates that knowing danger signs may be an essential step towards behavioral change. This opens up possibilities for a number of potential interventions, such as the need for community-based health promotion programs and health promotion efforts at the facility in all stages of a woman's reproductive life [27]. In addition, $\mathrm{BP} / \mathrm{CR}$ requires that health services are equipped to meet the increased demand for care $[28,29]$.

Women who had seen community health workers had better outcomes with regard to $\operatorname{BP} / C R[26,30]$. This may be explained by the high level of community recognition for community health workers in Rwanda [26]. Therefore, in general, and particularly in settings where other health workers are scarce, community health workers should receive appropriate recognition and support [26, 31, 32].

The strength of this study is that the interview took place shortly after birth, minimizing recall bias. The fact that these women were referred for complications makes for a selected study population and it is difficult to infer our results to the general pregnant population. Moreover, some women may recall or provide information about $\mathrm{BP} / \mathrm{CR}$ selectively, depending on their experience during birth or pregnancy outcome.

Nevertheless, we believe our study provides relevant information on possible opportunities to improve $\mathrm{BP} /$ CR. The fact that Rwanda is a densely-populated country with relatively widespread availability of health facilities (most women live less than an hour's travel away from a facility), combined with increasing government investment in community-based health programs, performancebased financing, innovative community health insurance and SMS-based alert systems are all reasons why better implementation of $\mathrm{BP} / \mathrm{CR}$ has the potential to lead to considerable improvements in pregnancy outcome in Rwanda [21, 33, 34].

\section{Conclusions}

This study revealed low levels of knowledge of obstetric danger signs and low levels of birth preparedness among women referred to a Rwandan hospital. Prenatal advice by community health workers and knowledge of danger signs during pregnancy are associated with being better prepared for birth. Investments in health promotion with regard to $\mathrm{BP} / \mathrm{CR}$, at all stages of a woman's reproductive life, and with support from community health workers are much needed. We recommend a review of the quality and methods of antenatal care education, including an evaluation of how multiparous women are also to benefit from such education, in order to improve the effectiveness of $\mathrm{BP} / \mathrm{CR}$.

\section{Additional file}

Additional file 1: Consent form and questionnaire. Consent form as used in the study and questionnaire adapted from the 'Safe Motherhood questionnaire', as developed by the Maternal Neonatal Program of JHPIEGO, an affiliate of John Hopkins University. (DOCX 63 kb)

\section{Abbreviations}

aOR: Adjusted odds ratio; BP: Birth Preparedness; CR: Complication Readiness: OR: Odds ratio

\section{Acknowledgements}

We are grateful to the administration and staff of Ruhengeri hospital. We thank Desire Dusegimana, in particular, for support with data collection.

\section{Availability of data and materials}

The datasets used and/or analyzed during the current study are available from the corresponding author on reasonable request.

\section{Authors' contributions}

RK designed the study and wrote the protocol. PS, RK collected data, RK worked on the data analysis, assisted by JVR and TVdA. PS and RK drafted the manuscript. MvE, JvR and TvdA critically revised the draft manuscript. All authors read and approved the final manuscript.

\section{Ethics approval and consent to participate}

The Rwanda National Ethical Committee granted ethical clearance for the study (reference identification: No582/RNEC/2013). Interviewers explained to the participants the contents of a written consent form, including their right to withdraw from participating at any point during data collection. All participants provided written informed consent to participate. All interviews were conducted in private and every precaution was taken to ensure confidentiality.

\section{Competing interests}

Two of the authors are members of the editorial board of the journal: JVR is a section editor and TvdA an associate editor.

\section{Publisher's Note}

Springer Nature remains neutral with regard to jurisdictional claims in published maps and institutional affiliations.

\section{Author details}

'Department of Medical Humanities, VU University Medical Center, Amsterdam, the Netherlands. ${ }^{2}$ Department of Obstetrics and Gynecology, 
Ruhengeri Hospital, Musanze, Rwanda. ${ }^{3}$ Athena Institute, VU University Medical Center, Amsterdam, the Netherlands. ${ }^{4}$ Department of Obstetrics, Leiden University Medical Center, Leiden, the Netherlands.

Received: 8 June 2017 Accepted: 2 May 2018

Published online: 30 May 2018

\section{References}

1. Alkema L, Chou D, Hogan D, et al. United Nations Maternal Mortality Estimation Inter-Agency Group collaborators and technical advisory group. Global, regional, and national levels and trends in maternal mortality between 1990 and 2015, with scenario-based projections to 2030: a systematic analysis by the UN Maternal Mortality Estimation Inter-Agency Group. Lancet. 2016;387:462-74.

2. Sullivan TR, Hirst JE. Reducing maternal mortality: a review of progress and evidence-based strategies to achieve millennium development goal 5. Health Care Women Int. 2011;32:901-16.

3. Lozano $\mathrm{R}$, Wang $\mathrm{H}$, Foreman $\mathrm{KJ}$, et al. Progress towards millennium development goals 4 and 5 on maternal and child mortality: an updated systematic analysis. Lancet. 2011;378:1139-65.

4. Hailu M, Gebremariam A, Alemseged F, et al. Birth preparedness and complication readiness among pregnant women in southern Ethiopia. PLoS One. 2011;6:e21432.

5. JHPIEGO/Maternal and Neonatal Health Program. Birth Preparedness and Complication Readiness: A Matrix of Shared Responsibility. Baltimore: Jhpiego Maternal and Neonatal Health Program; 2001. http://www. commonhealth.in/neonatal-pdf/145.pdf.

6. McPherson RA, Khadka N, Moore JM, et al. Are birth-preparedness programmes effective? Results from a field trial in Siraha district, Nepal. Journal of Health Population and Nutrition. 2006:24:479-88.

7. Stanton CK. Methodological issues in the measurement of birth preparedness in support of safe motherhood. Eval Rev. 2004;28:179-200.

8. Hladik W, Kataaha P, Mermin J, et al. Prevalence and screening costs of hepatitis C virus among Ugandan blood donors. Tropical Med Int Health. 2006;11:951-4.

9. Soubeiga D, Gauvin L, Hatem MA, et al. Birth preparedness and complication readiness interventions to reduce maternal and neonata mortality in developing countries: systematic review and meta-analysis. BMC Pregnancy Childbirth. 2014;14:129.

10. Manandhar DS, Osrin D, Shrestha BP, et al. Members of the MIRA Makwanpur trial team. Effect of a participatory intervention with women's groups on birth outcomes in Nepal: cluster-randomised controlled trial. Lancet. 2004;364:970-9.

11. Belda SS, Gebremariam M. Birth preparedness, complication readiness and other determinants of place of delivery among mothers in Goba District, bale zone, south East Ethiopia. BMC Pregnancy Childbirth. 2016;16:73.

12. Agarwal S, Sethi V, Srivastava K, et al. Birth preparedness and complication readiness among slum women in Indore City, India. J Health Popul Nutr. 2010;28:383-91.

13. Urassa DP, Pembe AB, Mganga F. Birth preparedness and complication readiness among women in Mpwapwa district, Tanzania. Tanzania J Health Res. 2013;14:42-7.

14. Gebre M, Gebremariam A, Abebe TA. Birth preparedness and complication readiness among pregnant women in Duguna Fango District, Wolayta Zone, Ethiopia. PLoS One. 2015;10:e0137570.

15. Kaso M, Addisse M. Birth preparedness and complication readiness in robe Woreda, Arsi zone, Oromia region, Central Ethiopia: a cross-sectional study. Reprod Health. 2014;11:55.

16. Bintabara D, Mohamed M, Mghamba J, et al. Birth preparedness and complication readiness among recently delivered women in chamwino district, central Tanzania: a cross sectional study. Reprod Health. 2015;12:44.

17. Mushi $D$, Mpembeni $R$, Jahn A. Effectiveness of community based safe motherhood promoters in improving the utilization of obstetric care. The case of Mtwara Rural District in Tanzania. BMC Pregnancy Childbirth. 2010;10:14

18. Kabakyenga JK, Östergren PO, Turyakira E, et al. Knowledge of obstetric danger signs and birth preparedness practices among women in rural Uganda. Reprod Health. 2011;8:33

19. Moran AC, Sangli G, Dineed R, et al. Birth preparedness for maternal health findings from Koupela district, Burkina Faso. J Health Pop Nutr. 2006;24:489-97.

20. Rwandan Ministry of Health: National Reproductive Health Policy. Kigali, Rwanda; 2003
21. Ngabo F, Banamwana R, Nyirasafali D, et al. Every death counts: use of maternal death audit data for decision making to save the lives of mothers in Rwanda. Pan Africa Medical Journal. 2012;13:31.

22. National Institute of Statistics of Rwanda. Demographic and health survey 2005. 2005. Available at https://dhsprogram.com/pubs/pdf/FR183/FR183.pdf.

23. National Institute of Statistics of Rwanda. Rwanda demographic and health survey 2014-15. Calverton: ICF International; 2014.

24. National Institute of Statistics of Rwanda. Rwanda fourth population and housing census. Thematic report: characteristics of households and housing. Kigali, Rwanda. 2012.

25. Kakaire O, Kaye D, Osinde MO. Male involvement in birth preparedness and complication readiness for emergency obstetric referrals in rural Uganda. Reprod Health. 2011:8:12

26. Condo J, Mugeni C, Naughton B, et al. Rwanda's evolving community health worker system: a qualitative assessment of client and provider perspectives. Hum Resour Health. 2014;12:71.

27. Edmonds JK, Paul M, Sibley L. Determinants of place of birth decisions in uncomplicated childbirth in Bangladesh: an empirical study. Midwifery. 2012;28:554-60

28. Solnes Miltenburg A, Roggeveen $Y$, van Elteren $M$, et al. A protocol for a systematic review of birth preparedness and complication readiness programs. Syst Rev. 2013:2:11.

29. Solnes Miltenburg A, Roggeveen $Y$, Shields $L$, et al. Impact of birth preparedness and complication readiness interventions on birth with a skilled attendant: a systematic review. PLoS One. 2015;10(11):e0143382.

30. August F, Pembe $A B$, Mpembeni $R$, et al. Community health workers can improve male involvement in maternal health: evidence from rural Tanzania. Glob Health Action. 2016;9:30064.

31. Haver J, Brieger W, Zoungrana J, et al. Experiences engaging community health workers to provide maternal and newborn health services: implementation of four programs. Int J Gynecol Obstet. 2015;130:S32-9.

32. Lassi ZS, Bhutta Z. Community-based intervention packages for reducing maternal and neonatal morbidity and mortality and improving neonatal outcomes. Cochrane Database Syst Rev. 2015;11:CD007754

33. Rusa L, Ngirabega J, Janssen W, et al. Performance-based financing for better quality of services in Rwandan health centres: 3-year experience. Tropical Med Int Health. 2009:14:830-7.

34. Binagwaho A, Kyamanywa P, Farmer PE, et al. The human resources for health program in Rwanda-a new partnership. N Engl J Med. $2013 \cdot 369 \cdot 2054-9$

\section{Ready to submit your research? Choose BMC and benefit from:}

- fast, convenient online submission

- thorough peer review by experienced researchers in your field

- rapid publication on acceptance

- support for research data, including large and complex data types

- gold Open Access which fosters wider collaboration and increased citations

- maximum visibility for your research: over $100 \mathrm{M}$ website views per year

At BMC, research is always in progress.

Learn more biomedcentral.com/submissions 